University of Warwick institutional repository: http://go.warwick.ac.uk/wrap This paper is made available online in accordance with publisher policies. Please scroll down to view the document itself. Please refer to the repository record for this item and our policy information available from the repository home page for further information.

To see the final version of this paper please visit the publisher's website. Access to the published version may require a subscription.

Author(s): Waqar I. U. Ahmad and Hannah Bradby

Article Title: Locating ethnicity and health: exploring concepts and contexts

Year of publication: 2007

Link to published version: http://dx.doi.org/ 10.1111/j.1467-

9566.2007.01051.x

Publisher statement:"The definitive version is available at www.blackwell-synergy.com" 


\title{
Locating ethnicity and health: exploring concepts and contexts
}

Waqar Ahmad and Hannah Bradby

\begin{abstract}
With the rapid development of ethnicity and health as a field of sociological research, this paper seeks to re-evaluate the development of ideas around ethnicity, 'race' and culture and consider how they have been applied to question of health. Ethnicity as a social characteristic is contingent on the situation in which it is manifest. The process of marking 'other' ethnic groups includes stereotyping and racialisation, a process through which 'racial' or ethnic differences predominate to the exclusion of a consideration of social, economic and power relations. In the British context, the history of empire and medicine's justification of racist treatment of enslaved and colonised people, is relevant to understanding how ethnic and cultural difference have come to be essentialised and pathologised. While longstanding, immigration to Britain only became a mass phenomenon after World War II, with settlement patterns following employment opportunities and kinship alliances, diversity of settlement patterns reflects labour needs in local economies and patronage of family and friends. States have a longstanding history of 'managing' diversity, sometimes essentialising differences between groups, at other times tackling disadvantage and discrimination experiences by certain ethnic groups through policy action.
\end{abstract}

Sociologists of health were slow to study ethnicity, with initial research coming from tropical disease specialists. The tendency of medicine to pathologise minority cultures is explored through case studies of the approach to rickets and the assessment of health risks associated with consanguineous marriage. Anti-racist approaches have encouraged the consideration of discrimination against and socioeconomic position of minorities. The field has developed with work on nomenclature and the operationalisation of ethnic identity, necessary to study health inequalities between ethnic groups and paying due heed to the contribution of socioeconomic position and racism to group experiences. Research into chronic conditions with complex analysis of a number of distinct contributory variables has been published of late. However, the excessive focus on South Asians and the record of measuring, analysing, but not necessarily tackling health disadvantage, are problems that remain to be addressed.

\section{Introduction}

Understanding notions and experiences of health and illness are central concerns of this journal. To understand and locate a variety of social phenomena, sociologists have explored the role of social, cultural and economic divisions. Sociologists of health too have analysed health and illness experiences by class, age, gender, sexuality, physical or learning impairment - and increasingly by 'race', 'culture' and 
'ethnicity'. Divisions of various orders are a given feature of industrial societies and the arrival of migrants, travellers or scholars from outside provides further dimensions to understand and manage. In the British Isles, and particularly England, with a longstanding, stable Anglo-Saxon population, and a national character imbued with a colonial past, minority ethnic identity has particular meaning. The post-World War II mass migration was met, in Britain, with ambivalence and hostility coupled, simultaneously, with assumptions that the white privileged position would persist and yet immigrants would assimilate to the British way of life.

This paper is not aimed at providing an overview of literature and debates on ethnicity and health. Such overviews are available elsewhere (Smaje 1995; Davey Smith et al 2000b). Our aim is to locate ethnicity and health in an appropriate context by considering how conceptual and policy apparatus has developed over recent decades. We therefore start with a discussion of how 'race' and 'ethnicity' have been conceptualised, articulated and employed historically and across cultures. The management of ethnic diversity is a key policy concern for most industrialised countries. We discuss the key trends and developments in the history of ethnicity and health in Britain. This leads to a discussion of how sociologists of health have responded to an increasingly ethnically diverse Britain, with an interest in both the positive developments and the areas that have been neglected. Finally, we introduce the papers selected for this Monograph which make distinctive contributions to the literature by extending some of the debates introduced in this opening paper.

\section{Locating ethnicity, culture and 'race'}

Like 'community', 'ethnicity' is an over-employed term, sometimes used with such imprecision that it risks losing its analytical value. Isajiw (1974) identified over 70 elements in defining ethnicity in US and Canadian literature between 1945 and 1971, of which ancestry, culture, language, 'race' and religion were most prominent. Others emphasise 'ethnicity' as an identification articulated through negotiating boundary and social processes, requiring both self-affirmation but also others' acceptance of such claims. Ethnicity is thus a dynamic concept, characterised by its relationship to forms of heritage (national, linguistic, cultural), notions of belonging and external recognition of such claims, but also by its malleability, flexibility and situationality. Contemporary notions of 'ethnicity' show it as a marker of identity, vehicle for community mobilisation and a possible indicator of disadvantage, discrimination or privilege. How notions of ethnic identity play in time and space may vary. For example, in Pakistan, ethnic relations take on a regional and linguistic flavour - ethnic conflicts in the country continue to be termed 'lissani' (language) conflicts. Canada gives French and British speaking people secure status as 'founding peoples', with French and English defined as 'official' languages. Indigenous 'First Nationals', enjoy a variety of legal protections, and yet remain economically and socially marginal in Canadian 
society. Similarly, in the US and Australia, being indigenous to a land equates with a socioeconomic status even worse than many of the recently arrived minorities. In most countries ethnic minority status, often deriving from having migrated from elsewhere, goes hand in hand with social, economic and health disadvantage.

Ethnic identity can be powerfully related to access to resources such that the formation, maintenance and transformation of ethnic relations is crucial to wellbeing. The transformation of inter-ethnic group relations sometimes occur through extreme violence: the slaughter of Tutsies by Hutus in Rwanda; of Bosnian Muslims by their neighbours; the apparently un-ending war between Tamil Tigers and the Sinhalese dominated government in Sri Lanka, to give a few recent examples. Referring to conflicts in East Asia, Mackerras (2003) argues that ethnic conflict may have replaced ideological conflict since the end of the cold war. While he may be overstating the case, it is clear that ethnic identity cannot be ignored in any meaningful contemporary analysis of relations between groups as well as between nations.

Historically, the pseudoscientific notion of 'race', supported by both science and Christianity, created hierarchies of people and justified slavery, bonded labour and colonialism. Science and the Church decreed such oppression to be in the best interests of the colonized and the enslaved. Colonising and enslaving people has been justified as a means of civilising savages and as a means of saving their souls. The contention that slavery and colonisation benefit the slaves and colonised has also been used to oppose the abolition of slavery in the American South and to prevent colonized countries from gaining the right to self-rule. This is illustrated by the following paraphrasing of the fears expressed by the white elite about the abolition of slavery in the United States.

Enlarged freedom, too often ending in licence, excessive use of stimulants, excitement of emotions, already unduly developed [could lead to insanity. The black people] are removed from much of the mental excitement to which the free population...is necessarily exposed in the daily routine of life, not to mention the liability of the latter to the influence of the agitating novelties of religion, the intensity of political discussion... They were taught from infancy obedience and self control... The cause of insanity and other diseases with them now, from which they were exempted in slavery, is the removal of all healthful restraints that formerly surrounded them (Littlewood and Lipsedge, 1989: 37-8).

Medicine was a strong ally in giving racist systems of thought a scientific gloss. Entirely rational actions, such as running away from a slave master or disrupting the slave system were medicalised with the invention of new diagnoses, respectively drapetomaina (an 'irrational' desire of slaves to run away from 
their masters), and dysaethesia Aethiopica (or rascality) (Littlewood and Lipsedge, 1989). While freedom from slavery was opposed in the American South, on the grounds of threats to the mental well being of the enslaved, decolonisation too was deemed dangerous to the natives. In Egypt, for example, Lord Cromer opposed independence on the basis that Egyptian society possessed insufficient democratic maturity and was guilty of poor treatment of women. Simultaneously, and with no sense of irony, he stopped an indigenous Egyptian movement for women's education as disruptive and counter-productive and, in Britain, staunchly opposed the Suffragette movement (Ahmed 1992).

While hierarchical, immutable categories of 'race' are no longer explicitly used to differentiate between groups, many features of racial thinking have permeated concepts of ethnicity and culture. Culture is often referred to as if it possesses primordial, innate and immutable features which manifest as properties of specific ethnic groups. However, the desire to attribute particular characteristics to other groups, and to denigrate those characteristics is not unique to Western societies. Growing up in rural Pakistan, WA 'knew' that the service castes such as 'mirasis' were inappropriately jovial, assured to be a sign of mental immaturity, the 'jolahas' were inherently cowardly and could not be trusted in times of danger, and the 'musallies' were dull, fit only for menial labour. The 'mirasis' were story-tellers and musicians and the 'jolahas' were weavers. Both groups were often better educated than the 'zamindars' (land-lord farmers) and skilled in their occupations. But this did nothing to challenge their institutionalised oppression at the hands of the dominant 'zamindars' to whom they provided a variety of routine and life-cycle related services in exchange for land for their houses, fodder for their animals and a share of the harvest.

Culture as a presumed primordial feature allows the same justification of unique and immutable nature of particular groups that 'race' allowed previously. 'Ethnicity' and 'culture' take on 'social meanings and importance when physical and cultural traits are paired with social attributes, such as intellectual, moral or behavioural characteristics' (Li 1999: 7). Barker, in an influential book, argued that cultural or 'new' racism offered justification for hostility towards 'others' by locating such hostility in our 'nature' and downplaying the role of politics and economy:

Nations, on this view, are not built out of politics, or economics, but of human nature. It is our biology, our instinct, to defend our way of life, traditions and customs against outsiders, not because they are inferior, but because they are part of different cultures (Barker, 1981: 23).

Li (1999:4) notes that: 
This line of reasoning puts disadvantaged groups in an even more disadvantaged position since their culture becomes the source of their misfortunes. Thus, the economic problems of First Nations [indigenous Canadians] is often seen as caused by Native people's own ineptitudes and cultural inadequacies.

Using culture and ethnicity as an explanation of inequality between groups distorts perceptions of how ethnic relations, and the related inequities of power are produced. Defined by those in power, the disadvantage of minority ethnic groups too often continues to be seen as 'caused' by their diseased genetic and dysfunctional cultural inheritance. Notions of biology and culture mingle in a messy but complementary mortar, cementing inferiority of some, while conveniently absolving powerful groups and states from responsibility. Such thinking has seriously influenced definitions of health and care needs of minority ethnic groups in Britain, and elsewhere.

\section{Ethnic diversity and its management in Britain}

The presence of 'blacks' and 'coloureds' in the UK is not new. Given Britain's central involvement in the slave trade, its role as a major colonial power, and the size, reach and labour needs of its navy, this is not surprising. There were such sizable numbers of non-white people in Britain in the $16^{\text {th }}$ Century as to worry Queen Elizabeth I that they were consuming welfare rightfully belonging to her loyal and deserving (white) subjects. She ordered a mass expulsion of such people from her land. These themes of whiteness being linked to belonging, citizenship and entitlement to welfare relief have remained common features in relation to minority ethnic life in Britain ever since: access to health and other services remains intrinsically linked to claims of citizenship, with health and social care professionals increasingly required by the state to act as a second (often reluctant) line of immigration control. Britain's ports had settlements of non-white sailors and merchants before, and since, the $16^{\text {th }}$ Century, while high society has long included the odd 'coloured' nabob. In the early $20^{\text {th }}$ century British Universities and Inns of Law had the elite from the colonies being trained as the transitional or buffer classes between the natives and the white master class and increasing numbers of both workers and students were arriving from the colonies as the century progressed. It is perhaps ironic, that the death of British imperialism in South Asia was plotted by some of these visitors, with the chief architects of Indian and Pakistani independence - Iqbal, Gandhi, Nehru and Jinnah - all students or legal pupils in London, Oxford or Cambridge in the early 1900s.

Mass migration of people from the ex-colonies, however, is a relatively recent phenomenon. The need to rebuild Britain following World War II, the demands of an expanding economy, and the development of the welfare state required labour on a scale that could not be provided locally. The arrival of the Empire 
Windrush in 1946 from the Caribbean, to Tilbury in Essex, carrying some 500 men and women migrants, remains the iconic symbol of the start of mass colonial immigration to Britain. Migration, with its hey day in 1960s, followed relatively predictable patterns, dictated by the needs of local and regional industries and driven by networks and patronage more than direct recruitment in the ex-colonies. This period of economic expansion meant that in spite of blatant racist discrimination - in employment, health, housing and other services - new arrivals could secure initial employment and move jobs easily.

The needs of the local economy and patronage of fellow villagers or family explained the patterns of settlement of different minority ethnic groups more than other factors. Caribbeans settled in large numbers in London and were employed on public transport and in hospitals. Their settlement patterns demonstrate the importance of identities associated with particular islands, with Jamaicans, St Lucians and so on settling in small enclaves alongside friends and kin folk of the same island. Indians too arrived in large numbers in 1960s. A diverse community, their settlement patterns were more scattered than Caribbeans in terms of residential location and the industries in which they gained employment. The socalled 'East African Asians' entered Britain in the 1970s. A predominantly business community, and British passport holders, they sought resettlement in Britain following expulsions from Uganda, Kenya and Tanzania. Pakistanis, a more homogenous group dominated by those with backgrounds as small scale land-owning farmers, were recruited to provide semi-skilled labour in steel industry in the Midlands and textile industry in the northern belt running between Manchester in the west, through the Pennine towns, to Bradford and Leeds in the east. The Chinese arrived in various phases, opting predominantly to settle into family run restaurant and take away businesses, and remain highly dispersed with 'Chinatowns' in London and Manchester acting as cultural and community hubs. Bangladeshis arrived after the other major groups in the late 1970s when employment opportunities and immigration opportunities were increasingly restricted. This had an impact on their ability to accumulate capital and to be joined by their families. Family formation and unification followed in the next couple of decades and for many, remains an unfinished business.

This story of migration to and settlement in Britain in the second half of the twentieth century has shown that the fortunes of certain communities have been inextricably tied to certain industries and regions - decline in these industries, such as textiles in northern England, has had a disproportionate impact on some minorities, while having little or no effect on others. For example, the heavy concentration of migrants from Pakistan in these industries and relative homogeneity of their skills meant that large numbers suffered from the rapid decline in regional textile industry. Communities with greater internal diversity, which settled in a number of different regions and industries, such as migrants from India, were better able to respond to changes in the fortunes of particular industries. Equally, cities 
and regions with diverse industrial bases fared better in both cushioning partial industrial decline and in reinventing themselves through growth in new industries. Settlement patterns have had an impact on the availability of cultural resources and support networks, for instance social and cultural isolation is a key issue for the highly dispersed Chinese community, whereas Bangladeshis in East London, Indians in Leicester or Pakistanis in Bradford do not face this problem. However, the advantages of areas where minorities are highly concentrated have to be considered alongside disadvantages.

At the time of the 2001 Census, ethnic minorities constituted 7.9 per cent of Britain's population (or 4.6 million people). They are concentrated in the major urban areas, with $45 \%$ in London alone. Their age profile is younger compared to the white population and 50\% of Britain's Indian, Pakistani, Bangladeshi, Black Caribbean and Black African origin people are now British born. While there is greater diversity within minority populations than between them, overall (with some exceptions) minority ethnic groups do worse than their white fellow citizens in health, employment, earnings, education and housing.

Ethnic concentration has received attention by academics, policy makers and politicians. The British state has benefited from the emerging ethnic enclaves in Britain from the 1960s onwards in that concentration in particular neighbourhoods enabled the establishment of voluntary sector provision of welfare services within and for these minority communities (Rex 1991). Concentration has allowed the development of community networks, economic activity, community resources, reaffirmation of positive self identity and resources for its maintenance. Migrants and minorities (re)create structures and institutions which allowed the maintenance and reproduction of cherished cultural and religious values. Religious and community institutions as well as established systems of mutual support took rapid root in these communities in British towns and cities. Werbner (1990) notes the importance of family and community networks in the establishment and success of minority ethnic businesses. Such concentration potentially acts as a buffer against prejudice and racism, provides role models, accords status to individuals for skills or knowledge not acknowledged outside the community, offers social and moral support, and provides resources for the recreation of community. But all this happens at a price, including in terms of health.

Ethnic strife and street disturbances in the 1980s and more recently in 2001, brought attention to the 'problem' of such concentration, referred to negatively as 'segregation'. The Chairman of the Commission for Racial Equality, the official watchdog in this field, in a much hyped, but ill-informed speech warned the nation that Britain was 'sleepwalking to segregation' - he painted a picture of US style segregated ghettos and no-go areas (Philips 2005). The picture of 'parallel' universes, un-integrated young minority ethnic people and of cultural rift between generations, that he painted, also emerges in a 
plethora of official reports into the 2001 street disturbances. However, the evidence suggests a different, more complex picture in which deprivation and oppression as well as contestations over identity and territory play a significant role. Amin (2002) identifies four main reasons for street fighting and disturbances: the increasing activity by the far right and often violent, British National Party in areas of Pakistani and Bangladeshi concentration; prolonged heavy handed policing targeted against Asian youth, combined with little if any protection against racist activity; inflammatory media reporting of Asian-led crime and violence; and young Asians' anger over political marginalization and paternalism of their leaders. Amin notes that by the 1990s, the new generation of British-born and bred young South Asians in the northern towns, were unwilling to accept the second class status endured by their elders. The street violence was by South Asian young people was thus a claim to Britishness and their way of defending their streets from racists, almost exclusively from outside of their areas.

The exceptionally punitive sentencing meted out to the Asian young people involved in, what they regarded as, the defence of their streets from racist British National Party and racist police, confirmed for many that the police and the judiciary are there to control their communities without offering them protection.

While high concentration of minority ethnic communities in specific areas may have been over-played as a cause of street disturbances, or as a harbinger of an ethnically segregated Britain, it merits attention for other reasons. The areas where disturbances have occurred suffer multiple deprivation: over two-thirds of minority ethnic people in Britain live in the 88 most deprived local authority districts, compared to $40 \%$ of the general population (NRU 2004). The problems that afflict these districts therefore have a disproportionate affect on minority ethnic groups. Around one third of all British children live in poverty - defined as having family income below $60 \%$ of the national average - compared to $74 \%$ of Pakistani and Bangladeshi children and $63 \%$ of Black Caribbean children. Such blatant and significant inequalities matter. Housing, public amenities, health and welfare services, employment opportunities and, perhaps most importantly, aspirations and expectations may all be poor in these areas. Primary care services, especially dental health provision, in such areas are extremely poor and since primary care acts as a conduit to secondary care, this neglect diminishes prospects for appropriate and timely secondary care.

Further, if, as is sometimes the case, white parents living in deprived areas are more successful in placing their children in better performing and predominantly white schools outside the area, the local schools can become almost exclusively non-white. This process represents a severe reduction of the opportunity 
for routine, everyday, mundane, and yet vital, inter-ethnic dialogue, and permits apathy or even hostility to develop between sections of communities whose interests and problems are often the same (Amin 2002). Social solidarity may therefore be damaged alongside the life chances of both the majority and the minority communities. We discuss the culture of 'special provision' and 'anti-racist' approaches below.

\section{Ethnicity, health and care}

Early interest in minority ethnic health came from public health and tropical medicine specialists with an initial focus on protecting the British population from diseases which could be imported by immigrants. This was followed by an interest in the exotic and peculiar, and above all that which was 'different' from the British 'norm'. The focus on diseases and conditions peculiar to minorities was unfortunate in that it had the effect of ignoring both the health issues that concerned the communities themselves and the diseases which afflicted the largest numbers of people in these communities. Instead, and not surprisingly, the focus reflected the prevalent racial and cultural stereotypes and fears, from deficient parenting in relation to child health, restrictive cultures and their impact on nutritional deficiency among South Asians, low pain thresholds and proneness to addiction to pain killers among African Caribbean sickle cell sufferers, to dangerous and irresponsible behaviour on part of Muslim consanguineous parents 'causing havoc' of death and disability among their off-spring.

The focus on deficient minority culture turns conditions without any necessary connection to a given culture into 'ethnic' conditions, with assumed racial or cultural features. Conditions thus become racialised, with ethnic or cultural features over-emphasised to the extent that the commonly understood aetiological or prognostic factors are ignored and new solutions invented, aimed at changing the presumed deficient cultures of the communities concerned. The victims are thus blamed for their own ills, as illustrated in the following two examples. First, vitamin D deficiency in children was endemic in poor British population of the mid $20^{\text {th }}$ Century. Pictures of bowed legged children adorned basic clinical medicine text books of the period. Eradication owed much to better outdoor facilities for children and, in particular, the fortification of margarine with vitamin D and the universal free availability of milk in schools. When rickets appeared in South Asians in the 1970s, after it had largely disappeared in the majority population, it was re-cast as an exotic disease (Donovan 1984). Now termed 'Asian rickets', its cause was located in deficient South Asian diets and codes of gender and dress. It was also assumed that South Asian skins were too pigmented to convert northern hemisphere sunlight into vitamin D and that modest clothing further hampered the process. It was suggested that 'the longterm answer to Asian rickets probably lies in health education and a change towards the Western diet and lifestyle' (Goel et al 
1981: 405). Remarkably, for some considerable time, the solution that worked for the white population fortification of a staple diet with vitamin D - was considered inappropriate on the pretext that such fortification of South Asian staple diets (ghee or chapatti flour) may lead to vitamin D toxicity. Why toxicity was not an issue in the case of fortification of margarine was never discussed.

Second, a more recent fascination in Britain has concerned consanguinity, the practice of marriage between blood relatives. Marriage between first cousins was quite acceptable in Britain and among the well known cases of cousin marriages was Charles Darwin's marriage to Emma Wedgwood, with whom he had ten children. Cousin marriage is a common and favoured pattern of family formation in Britain among South Asian Muslims and remains normal in many parts of the world. In current day Britain, first cousin marriage has become highly stigmatised, even bordering on incest, such that true prevalence among the ethnic majority is likely to be under-estimated. The presumed ill effects of consanguineous marriage among South Asians have been indicated as 'explaining' a variety of ills, from bleeding disorders, to heightened rates of physical impairments and deafness. For certain recessively inherited genetic conditions such as thalassaemia, marriages within a family group with a particular genotype will undoubtedly increase the chance of the two partners having the condition or being carriers and increase the statistical probability of passing on the genes and/or the condition to offspring. In relation to South Asian, especially Pakistani parents, there is a marked tendency on the part of health professionals to blame consanguinity for a child's ills, irrespective of the known mechanisms of causation and often without clinicians confirming whether or not parents are in fact blood relatives. South Asian parents of thalassaemic children were regularly told that the child's condition has been 'caused' by parental consanguinity and yet in several cases, parents were not in a consanguineous marriage and were puzzled by this information (Ahmad et al 2000). Some parents did not make the link between consanguinity 'causing' thalassaemia and the genetic transmission of the condition, so the attribution of cause did not inform futher reproductive decisions. Clinicians' emphasis on consanguinity causing various conditions was based on a moral belief about the evil of consanguinity, rather than an appraisal of the available evidence (Ahmad et al 2000). This is illustrated by the very different approach to the explanation of the transmission of sickle cell disorder, like thalassaemia a recessively inherited condition with the same mode of transmission. The parents of children with sickle cell disorder, mostly of African Caribbean origin, were given historical explanations about the sickle cell gene being endemic in Western Africa, or were simply told about the transmission of recessive disorders. For many African Caribbeans, these explanation under-lined and affirmed their heritage and identity, whereas explanations of thalassaemia focussing on consanguinity offered to South Asians undermined their cultural values and induced self blame (Ahmad et al, 2000). Clinicians' anxieties around consanguinity, this time in relation to heightened rates of deafness among children, were exemplified in the following quote, which followed a tirade 
against arranged marriages as a practice alien to British culture, and the need to protect young British Asian women from such oppression:

And it's that one factor [arranged marriage between consanguines] which is causing this awful dilemma of deafness. Whether it's responsible for some of the other factors that we have, mainly multiple congenital abnormalities we see in this group of children I cannot comment on that... But it seems to me a dire tragedy that this isn't being rectified...I think that it's a shame when a culture can't see that something they're doing which is near and dear to their wishes is causing such havoc among their children. (Ahmad et al, 2000: 39-40)

Health care practitioners, while well meaning, were revisiting the arguments which previous generations of colonists, policy makers and practitioners had employed to convince themselves that the ills of the 'other' were located in the other's own diseased genes or pathological culture, and that they, as enlightened Westerners, were in a privileged position to define what is in the best interests of these children and communities. The communities are, as before, being maligned and denied both respect for their values and their citizenship rights. Worst still, their legitimate health needs are undermined by a racist discourse, employed by powerful health services gatekeepers such that undue attention is focussed on inappropriate issues, which distracts from the factors underlying significant inequities in health. The difficulty of avoiding a culture-blaming effect when considering the connection between minority culture and its relationship with specific health outcomes is described in Rocheron's (1988) analysis of the high profile 'Asian Mother and Baby Campaign'.

Much of the literature on ethnicity and health in Britain is not social scientific, but medical and epidemiological. In exploring population and environmental characteristics, epidemiology has a strong interest in comparative studies and the notion of relative risk. Comparisons of minority ethnic communities with the majority community 'norm' in terms of morbidity, mortality or health related behaviour, including use of services, have been a common form of research which tends to find excess morbidity, mortality, or deleterious health behaviour among the minority in question. Two problems arise from this approach. First, the impression is given that minority ethnic health should only be explored as a comparative problem, rather than as significant or interesting phenomenon in its own right. Second, the focus tends to be on those conditions where minority ethnic groups have a raised incidence or prevalence of a condition, irrespective of whether this in itself has significance for the minority or the majority population. For example, while tuberculosis rates remain higher among some minority ethnic groups compared with the white population, this is of limited significance as the overall prevalence rates are relatively low and improved treatment has reduced mortality from tuberculosis. In contrast, cancers which account for around 1/6th of all deaths among minority ethnic groups are 
neglected as the relative prevalence rates for minorities are lower than in the white population. This emphasis on 'relative risk', and thus 'treatment' of heightened risk, has parallels with the culture of 'special initiatives' in health and welfare services.

The culture of special initiatives in the National Health Service was located in the crude multiculturalism of the 1970s, which stripped minority cultures of their complexity, contingency and dynamism and presented them as static, homogenous artefacts, whereby all members of a 'culture' were assumed to share common features. Cultural guidebooks mushroomed in state services, educating service providers about the peculiarities of 'ethnic' cultures. Racism and discrimination did not fit well with this formulation of ethnic minority 'special' needs. If the difference between the majority and minority cultures could be identified, state provision should address this 'difference' either through its own special initiatives or by cultivating the minority ethnic voluntary sector. Rex (1991) notes that the British state keenly supported the development of minority ethnic voluntary organisations soon after the start of the large scale migration in the 1960s and 1970s. Such organisations were regarded as efficient, cheap and often popular means of meeting the 'additionality', located in cultural or linguistic difference, and which could not be met by the state or established voluntary sectors. The definition of minority ethnic needs in terms of 'cultural difference' gave important impetus to both separate provision (supported through earmarked streams of state funding) and statutory sector funded 'special initiatives', to support transition to assimilation into the British society. Such 'special projects' had two advantages for the statutory sector. By locating minorities' needs in their own presumed cultural deviance the statutory sector could absolve itself of any responsibility to change. Second, the provision of separate services was a considerably cheaper and a more high-profile option. The authority could be seen to be taking action at little cost and with little disruption to mainstream services.

The policy and academic backlash against 'multiculturalism' as an academic discourse and a formal policy framework was located in a critique which argued that multiculturalism neglected the fundamental causes of disadvantage, which were located in the deeply ingrained 'racism' within British society. The central tenet of this argument was that the colonial history and ideology of white superiority are deeply embedded in British institutions and popular culture and disadvantage the 'racialised' (that is seen predominantly in terms of their 'racial' difference) ex-colonial subjects. Fundamental to this critique was the notion of 'institutional racism', that is the routine expectations, processes and practices of institutions which disadvantage the racialised groups irrespective of individual functionaries being racist. The movement was supported by a new form of academic literature (Hall 1978; CCCS 1982; Sivanandan 1982) and a strong policy current. The latter included the Greater London Council, led by Ken Livingston (the current Mayor of London), the Central Council for Education and Training in Social 
Work and several local authorities who spent time and effort in articulating and implementing anti-racist policies, often in the face of abuse from tabloid press for being 'anti-white' and criticism from white staff and users. The policy mood was one of creating, sometimes uncomfortable 'alliances of the dispossessed' and articulating inclusive notions of solidarity which privileged colour over culture or religion. The term 'black' symbolised this alliance of the 'racialised'. In 'anti-racism', tackling racism was only possible collectively and any recognition of diversity by religion or culture was to fragment and disempower the movement and fall into the 'culturalist' trap. The policy movement lasted into the 1980s when, under increasing opprobrium and resistance from an overtly hostile, Conservative-led central state and challenges from within the alliance, including over the importance of religion, it came to a faltering end. However, there remains an acceptance (albeit contested) that racism and racial disadvantage are key and enduring features of British life which is supported by significant new legislation in the form of the Race Relations (Amendment) Act (2001) which places a duty of care on public services to ensure racial equality in their organisations.

\section{The sociology of ethnicity and health}

Sociologists of health arrived on this scene relatively late compared to other branches of British sociology. By the 1970s, 'race relations' had developed into a significant field in British sociology, with major works already published by John Rex, Robert Moore (Rex and Moore 1969), Charles Husband (Hartman and Husband, 1974) and Michael Banton (1977). The first generation of 'race relations' doctoral graduates, such as Anwar (1979) and Saifullah Khan (1979), both of whom studied under Sheila Allen at Bradford University, were publishing their works in the 1970s. The importance of 'race relations' as a field of study was reflected in published outputs from the Universities of Aston, Bradford, Birmingham, Bristol and later Warwick and the development of Masters and Undergraduate courses at these and other Universities. By the 1980s a powerful critique of dominant academic and policy approaches to 'race relations' was emerging from the influential Centre for Contemporary Cultural Studies, Birmingham University, under Stuart Hall (CCCS 1982; Hall 1982), the Institute of Race Relations, under A. Sivanandan (Sivanandan 1982), and others.

Meanwhile sociologists of health and illness continued to ignore ethnicity and 'race'. Two important interventions in the mid 1980s were papers by Jenny Donovan (1984) and Maggie Pearson (1986), both highlighting problems with extant literature on ethnicity and health and the importance of locating minority ethnic health and care needs in the context of socioeconomic disadvantage, racial discrimination, racialisation and minority status. However, the field developed slowly, tempting one of the authors (Ahmad 1992) to publish a provocation in the medical sociology group's newsletter, entitled 'Is medical sociology an ostrich?', arguing that both the discipline and its mouthpieces, including this 
journal, had shunned their responsibility to reflect in their work the ethnic and religious diversity in modern Britain.

Recent years, however, have seen an increase in sociological work focusing on minority ethnic health. A number of areas of improvement can be highlighted. First, learning from developments in the sociologies of ethnicity, migration, identity, nationalism and citizenship, researchers have contributed to literature on nomenclature, and operationalising definitions such as ethnicity, ethnic classifications, 'race' and racism. Aspinall (1997) has published interesting work on ethnic classifications in the 2001 Census, and the use of 'ethnicity' as a variable in health research. Bradby $(1995 ; 2003)$ has explored the complexities and contradictions of conceptualising ethnicity and racism. Nazroo (1997), Smaje (1995; 1996) and others have introduced sophistication to debates around ethnic health inequalities. Ahmad (1999) has highlighted the complex and contingent nature of culture and the importance of context in the choice of identity definitions to be employed in research and practice. Bhopal (e.g. 1997) has argued for a more considered approach to research in this area within epidemiology.

Second, a number of significant studies have explored ethnic differentials in morbidity, mortality and access to health services. Davey Smith et al (2000a), based on an extensive qualitative study, explored challenges involved in developing appropriate measures of socioeconomic position. Nazroo (1997, 1998) was among the first to have a significant focus on the interplay between ethnicity and socioeconomic position, using data from the Policy Studies Institute's Fourth Ethnic Minority Survey which included a nationally representative sample of the numerically significant minority ethnic groups. This work demonstrated that to a significant extent, ethnic inequalities are reduced or eradicated once differences in socioeconomic conditions are taken into account. Nazroo also argued that given the difficulties of applying simple measures of socioeconomic position across cultures (a point developed in depth by Davey Smith et al 2000a), composite measures of socioeconomic status may be preferable. The effect of the experience of racism on ill health, independent of class has been demonstrated by Karlsen and Nazroo (2002) and the potential impact of impoverished neighbourhood environment on minority ethnic health (Karlsen et al 2002) has been underlined. While these and other colleagues have introduced a critical edge to explorations of ethnicity and health, Smaje (1995), in a well argued book and paper (Smaje 1996), has warned against reducing ethnic inequalities in health and illness to socioeconomic factor differentials alone. These are significant (albeit belated) developments in the sociology of health and the literature on ethnicity and health.

Third, while British sociology of health has a proud tradition of studying the 'meaning' of health and illness, through careful qualitative studies of illness experience, especially of chronic illness (Bury 1991; Herzlich 1973; Williams 1993; Blaxter 2004), such literature has been lacking in relation to minority 
ethnic groups. The work of a group of researchers working with Ahmad and Atkin (Ahmad 2000; Ahmad et al 2000; Atkin and Ahmad 2000a, 2000b; Ahmad et al 2002) has made an important contribution in this field. Focusing on young people growing up with chronic conditions and physical impairments (deafness, haemoglobinopathies, impairments) they explore how notions of identity are developed, maintained and policed; how the interface between users and providers is negotiated; and how professionals understand and manage ethnic difference. In another strand of their work (Katbamna et al 2004;), they explore the negotiation of caring responsibilities within communities, including the strategies that people living and dying with cancer employ to retain a sense of positive selfhood when identity is threatened by deteriorating, often leaky bodies (Chattoo and Ahmad 2003). This volume shows that other sociologists are now making valued contributions to the experience of chronic illness and disability in minority ethnic groups.

Fourth, the complexity of analysis is increasing in the study of ethnicity and health. Both qualitative (e.g. Bush et al 1998) and quantitative (e.g. Nazroo 1997) analysis has compared different minority groups against one another and with the majority. The inclusion of various minorities in a comparison hinders simplistic essentialising of the effect of minority cultures, and consequent culture-blaming tendencies. Furthermore, it can facilitate consideration of the complexity of how minority and majority cultures influence one another. Inter-ethnic comparisons that consider gender, as well as class as explanatory variables for health outcomes are a welcome development (Cooper 2002).

While we have witnessed improvements in both the level of sophistication and the extent of work published in this field in recent years, there remain several gaps. Much of the focus on research is on South Asians while several smaller groups remain under-researched. For example, among the established minority ethnic groups, there is a paucity of literature on Somalis and other Africans, those from the Middle East, Eastern Europeans and Latin Americans. Equally there is little health research on refugees and asylum seekers. As previously, it seems that sociology of health is waiting for other branches of British sociology and social policy to take the lead, before joining in.

Further, while in Britain we become ever more sophisticated at defining, documenting and monitoring racism and disadvantage, we seem to be no better at tackling such disadvantage. Recent evidence (Palmer and Kenway 2007) demonstrates that the gap in poverty between sections of the minority ethnic communities and the general population has not reduced for decades.

Finally, there is a greater acceptance in Britain that religion is an increasingly important variable in addressing ethnic relations. Sociology of health and illness remains relatively poor in this area. However, while we must recognise the importance of religion both in terms of its importance as a marker of 
identity and its links to ethnic relations, to socio-economic position and oppression, we must not allow it to become the new 'master identity', but rather keep it in play with other dimensions of identity and structural position (Bradby 2007).

\section{Introduction to the papers in this volume}

This volume offers a survey of current research in the field of the sociology of ethnicity, racism, health and illness in Britain and the US. The study of ethnicity and health is perhaps more clearly developed as a sub-field of medical sociology in Britain than elsewhere in Europe. British research has developed out of Marxist traditions of studying labour relations and an interest in whether the reserve army of labour drawn from the former colonies would develop a class consciousness. While Britain's obsession with class is not replicated in the US, 'race' has long been a highly significant social and economic division and therefore an important public health variable. The terms 'race' and ethnicity are used in the UK and the US, and yet they refer to somewhat different constellations of the various dimensions that the terms encompass (as discussed earlier). The search for a universally applicable code of terms is not feasible or appropriate in research which seeks to delineate the particularities as well as the generalisations of experience and outcome. The adoption of regularised terminology (even if it could be agreed) does not address the underlying historical and contemporary contrasts between the US and Britain which make simplistic comparison meaningless.

James Nazroo and colleagues' paper in this volume shows that the discontinuities in social and economic conditions of minorities do not render comparisons across the Atlantic impossible. The secondary analysis of data-sets from England and the US has allowed some conclusions to be drawn about the conditions which make migrants more and less likely to thrive in their new settings. Black, Caribbean and white Americans are compared with Caribbean and white English on self-assessed general health and the poorer health of English Caribbeans compared with their US counterparts suggests that the historical and economic context of a group's migration experience is an important consideration. Riley Bahr in his paper in this volume pursues the issue of health inequalities by ethnic group in seeking an 'explication [of] the residual racial gap in health remaining after adjustment for socioeconomic status and correlates of socioeconomic status'. Using detailed survey material on nutritional behaviours among Blacks and Whites in California, and the accumulated evidence of the links between nutrition and health outcomes, Riley Bahr suggests that at least some of the residual gap can be explained by Blacks having less healthy nutritional behaviours compared with Whites. The relationship between 'nutritional healthfulness' and 'race', independent of socioeconomic status, is linked to residential segregation and the lack of availability of healthier foods in poorer neighbourhoods where Blacks tend to live. 
The welcome attention being paid to common and chronic conditions among minority ethnic groups is illustrated in this volume by research on diabetes and depression. The well-researched nature of these conditions in the general population ensures that commonalities as well as divergence in their expression, experience and treatment among minorities can be explored. The longstanding discussion of the 'somatisation' of psychological conditions among minority groups in the Anglophone world has, at its crudest, implied that some cultures conceptualise bodily but not psychological suffering and therefore can only express distress in somatic terms. Mallinson and Popay's research based on White and South Asian adults' accounts of depression presents a more nuanced picture, with some variation in the metaphors used to express emotional distress between the groups, but in the context of considerable overlap in the types of narrative and symbolism employed. Similarly, in Seymour and colleagues' research with White and Chinese elders on their expectations of end of life care, there were many common themes reflecting people's concern for their families in the British urban environment, and the divergence, while of interest, was again subtle. Lawton and colleagues consider how people explain the genesis of their type 2 diabetes mellitus and, again, find similarity in White and South Asian accounts. They consider the effect that the researcher's cultural context has in shaping analysis and charge us with paying attention to the expectations that we bring to the research encounter.

Another welcome move, which takes institutional forms of discrimination seriously, is the interest in organisational features of health and welfare services which may disadvantage particular ethnic groups. The British NHS has formally acknowledged that interpretation should be available to ensure that services are delivered in an appropriate language; how this can be achieved equitably and economically has not yet been established. Greenhalgh and colleagues present their findings into how General Practices in London meet the language needs of their patients, viewing the interpreted consultation as an organisational routine and suggesting that variation in how this routine operates can be related to the type of General Practice. Salway and colleagues' secondary analysis of the Labour Force Survey focuses on variation across ethnic groups in claiming Disability Living Allowance. Here too similarities between groups were highlighted in terms of disincentives to claim the allowance, along with some differences between ethnic groups. However, the solution to the low uptake of the allowance by some groups is seen to lie in improving the information flow from the welfare agencies, rather than in rectifying the 'deficiencies' of minority culture.

\section{Acknowledgements}

Carol Capper ensured order during the process of commissioning and reviewing material for this monograph. Karl Atkin was generous and exceptionally prompt in providing comments on an earlier 
draft of this article. To both, our heartfelt thanks. We owe a great debt of gratitude to numerous referees who commented on successive drafts of the papers in this volume.

\section{References}

Ahmad, W.I.U. (1992) 'Is medical sociology an ostrich? reflections on 'race' and the sociology of health', Medical Sociology News, 17(2): 16-21.

Ahmad, W.I.U. (1999) 'Ethnicity and statistics: better than nothing or worse than nothing?' pp 124-131 in Dorling D and Simpson S (Eds) Statistics in Society, London: Edward Arnold.

Ahmad WIU (Ed) (2000) Ethnicity, Disability and Chronic Illness, Buckingham: Open University Press.

Ahmad WIU, Atkin K and Chamba R (2000) '"Causing havoc to their children": parental and professional perspectives on consanguinity and childhood disability', in Ahmad WIU (Ed) Ethnicity, Disability and Chronic Illness, Buckingham: Open University Press, p28-44.

Ahmad W.I.U., Atkin, K. and Jones, L. (2002) 'Being deaf and being other things: young Asian people negotiating identities', Social Science and Medicine, 55(10): 1757-1769.

Ahmed, L. (1992) Women and Gender in Islam, New Haven, CT and London: Yale University Press. Amin, A. (2002) Ethnicity and the multicultural city: living with diversity. Environment and Planning, 34:959-980.

Anwar, M. (1979) The Myth of Return, London: Heinemann.

Aspinall, P.J. (1997) The conceptual basis of ethnic group terminology and classification. Social Science and Medicine 45(5): 689-98.

Atkin, K. and Ahmad, W.I.U. (2000a) 'Pumping iron: compliance with chelation therapy among young people who have thalassaemia major', Sociology of Health and Illness 22(4): 500-24.

Atkin, K. and Ahmad, W.I.U. (2000b) Family caregiving and chronic illness: how parents cope with a child with a sickle cell disorder or thalassaemia. Health and Social Care in the Community 8(1): 57-69.

Barker, M. (1981) The New Racism, London: Junction Books.

Banton, M. (1977) The Idea of Race, London: Tavistock

Bhopal, R.S. (1997) Is health into ethnicity and health, racist, unsound or important science? British Medical Journal 314: 1751-6.

Blaxter M. (2004) Life narrative, health and identity. In Kelleher D and Leavey G (Eds) Identity and Health, London: Routledge.

Bradby, H. (1995) Ethnicity: not a black and white issue. Sociology of Health and Illness 17(3): 405-17. 
Bradby, H. (2003) Describing ethnicity in health research. Ethnicity and Health 8(1): 5-13.

Bradby, H. (2007 - in press) Watch out for the Aunties! Young British Asians' accounts of identity and substance use. Sociology of Health and Illness [Liz: can the page references be inserted here?]

Bury, M. (1991) The sociology of chronic illness. Sociology of Health and Illness 13(4): 451-65.

Bush, H., Williams, R., Bradby, H., Anderson, A., and Lean, M. (1998) Family Hospitality and Ethnic

Tradition Among South Asian, Italian and General Population Women in the West of Scotland.

Sociology of Health \& Illness 20 (3), 351-380.

Centre for Contemporary Cultural Studies (1982) The Empire Strikes Back, London: Heinemann

Chattoo, S., Ahmad, W.I.U. (2003) 'The meaning of cancer: illness, biography and identity' pp 19-36 in

D. Kelleher and G. Leavey (eds) Identity and Health, London: Routledge.

Cooper, H. (2002) 'Investigating socio-economic explanations for gender and ethnic inequalities in health', Social Science and Medicine, 54 (5): 693-706.

Davey Smith, G., Charsley K., Lambert H., Paul S., Fenton, S. and Ahmad, W.I.U. (2000a) 'Ethnicity, health and the meaning of socio economic position', in Graham H (Ed) Understanding Health Inequalities, Buckingham: Open University Press.

Davey Smith, G., Chaturvedi, N., Harding, S., Nazroo, J. and Williams, R. (2000b) Ethnic inequalities in health: a review of UK epidemiological literature. Critical Public Health 10(4): 375-408.

Donovan, J. (1984) Ethnicity and race: A research review. Social Science and Medicine 19, 7, 663-670.

Goel K.M., Campbell S., Logan R.W., Sweet E.M., Atttenburrow ,A. and Arneil, G.C. (1981) 'Reduced prevalence of rickets in Asian children in Glasgow', Lancet, 2: 405-06.

Hall, S. (1978) Policing the Crisis: Mugging, the State, and Law and Order. Basingstoke: Macmillan.

Hartman, P. and Husband, C. (1974) Racism and the Media, New Jersey: Rowman and Littlefield.

Herzlich, C. (1973) Health and Illness, London: Academic Press.

Isajiw, W. (1974) Definitions of ethnicity. Ethnicity 1: 11-24.

Karlsen, S. and Nazroo, J. (2002) Relation between racial discrimination, social class and health among ethnic minority groups. American Journal of Public Health 92(4): 624-631.

Karlsen, S., Nazroo, J. and Stephenson, R. (2002) Ethnicity, environment and health: putting health inequalities in their place. Social Science and Medicine 55(9): 1647-61.

Katbamna S., Ahmad, W.I.U., Bhakta, P., Baker, R., and Parker, G. (2004) Do they look after their own? Informal support for South Asian carers. Health and Social Care in the Community 12(5): 398-406.

Isajiw, W.W, (1974) Definitions of ethnicity. Ethnicity, 1: 111-124.

Li, Peter S. (1999) "Race and Ethnicity." In Peter S. Li (ed.), Race and Ethnic Relations in Canada. Toronto: Oxford University Press, 3-20.

Littlewood, R. and Lipsedge M. (1989) Aliens and Alienists. Ethnic Minorities and Psychiatry, London: Unwin Hyman. 
Mackerras, C. (2003) Ethnicity in Asia, London: Routledge.

Nazroo, J. (1997) The Health of Britain's Ethnic Minorities: Findings of a National Survey, London: Policy

Studies Institute.

Nazroo, J. (1998) Genetic, cultural and socioeconomic vulnerability? Explaining ethnic inequalities in health. Sociology of Health and Illness, 20(5): 710-730.

Neighbourhood Renewal Unit (2004) Race Equality and Neighbourhood Renewal, London: Office of the Deputy Prime Minister.

Palmer, G. and Kenway, P. (2007) Poverty Among Ethnic Groups: How and Why Does It Differ, York: Joseph Rowntree Foundation (available to download from www.jrf.org.uk)

Pearson, M. (1986) The politics of ethnic minority health studies. In T Rathwell and D Phillips (eds) Health, Race and Ethnicity, London: Croom Helm.

Philips, T. (2005) After 7/7: Sleepwalking to segretation. (Speech by the then Chair of the Commission for Racial Equality) http://www.cre.gov.uk/Default.aspx.LocID-0hgnew07s.RefLocID0hg00900c002.Lang-EN.htm (accessed 26 May 2007).

Rex, J. (1991) Ethnic Identity and Ethnic Mobilisation in Britain, Warwick: Centre for Research in Ethnic Relations.

Rex, J. and Moore, R. (1969) Race, Community and Conflict, Oxford: Oxford University Press (for the Institute of Race Relations)

Rocheron, Y. (1988) The Asian Mother and Baby Campaign: the construction of ethnic minority health needs. Critical Social Policy 22: 4-23

Saifullah Khan, V. (1979) Minority Families in Britain, Basingstoke, Macmillan.

Sivanandan, A. (1982) A Different Hunger: Writings on Black Resistance. London: Pluto Press.

Smaje, C. (1995) Health, Race and Ethnicity: Making Sense of the Evidence, London: Kings Fund.

Smaje, C. (1996) The ethnic patterning of health: new directions for theory and research. Sociology of Health and Illness 18(2): 139-71.

Werbner, P. (1990) The Migration Process: Capital, Gifts and Offerings Among British Pakistanis, Oxford: Berg. Williams, G. (1993) The genesis of chronic illness: narrative reconstructions. Sociology of Health and Illness 6: $175-200$. 